and tasteless character, which have been put into the market under different fancy names, have been discussed by various writers. But, curiously enough, little attention has been given to a variety of proteid which would seem to have stronger claims to notice than any other, if only on the grounds that it is more readily available and much cheaper than any proprietary food. And irrespective of these two not unimportant recommendations, the facts that cheese has in every form a higher proteid value than meat or any other albuminoid foodstuff; that when appropriately prepared it can be brought to table in as great a variety of dishes and in as appetising shapes as meat; that when properly selected and eaten it is eminently digestible; and lastly, that it is comparatively free from the purin and acetone producing elements which characterise other forms of animal proteid, should give it a strong claim to consideration in the dietetic treatment of glycosuria. It is true that von Noorden asserts in his illuminating work on the pathology and treatment of diabetes mellitus that feeding with casein is associated with glycosuria in a marked degree; but he also makes, in the same work, the paradoxical statement that casein does not contain any carbohydrates that can be split off in the process of digestion.

However we may attempt to reconcile these apparently conflicting statements, it is highly probable that they are to be in some degree explained by an oversight of the fact that cheese is as varied in its characteristics as is meat, and that even one kind of cheese may vary so much during the changes it undergoes in ripening that what is easily digestible at one stage may become very indigestible at a later one. Moreover, the change which the volatile fatty acids in particular undergo in the ripening of most kinds of cheese, when considered in combination with the possibility, on which von Noorden himself lays much stress, that they may, under the influence of a special ferment, split up into glucosides, increases the perplexity of this problem. That the indigestibility of fully ripe cheeses of the larger types is mainly due to the rancid character which their fatty acids acquire is certain, though there are other elements of ripe cheese which may help in producing this result. It is obvious therefore that the question of what is the true value of cheese as an element of the diet in diabetes in comparison with egg albumin, meat, and various forms of vegetable proteid, from all of which it is claimed that glucose can be derived under favourable conditions in the digestive process, requires to be answered in a more satisfactory way than has been yet done. Such an answer to be of any real value must be of a practical character and can be only given by medical practitioners who, having cases of diabetes under their observation, can contribute important information on the subject. This they can do by the careful dietetic administration, in measured quantities and under the best control conditions which the circumstances of each case allow, of a form of cheese, specially selected for the purpose, and by the estimation of the effects of a diet composed of such cheese in suitable quantities and with proper accompaniments on the elimination of sugar in the urine, for a sufficient time to allow of a trustworthy inference being drawn from the experiment.

For the reason above stated the value of the information to be derived from this inquiry will depend on the uniformity of character and composition of the cheese selected for it. The cheese should be one which, while containing a fair amount of butter fat, is free from any degree of rancidity. Moreover, it is desirable in view of the distaste which the diabetic palate easily acquires for any long-continued diet in which the ordinary forms of carbohydrates are absent, that the cheese should be of a kind in which, whilst it has no marked flavour of its own, it should be capable of being made as appetising as possible, either by the incorporation with it of unobjectionable flavouring ingredients or by the development of the special aroma which all cheese acquires under effective culinary treatment. Any medical practitioner who has a case of diabetes under his observation and who will take the trouble of explaining to his patient the way in which the cheese should be consumed and who will determine its effects upon the variation of sugar in the urine and on the weight of his patient may make a valuable contribution to clearing up this obscure but important problem. The interest of this inquiry is the greater because, as von Noorden himself points out, the explosion of glycosuria, when it does occur in a shape in which its true character cannot be overlooked, is in many cases only the climax of a long-continued metabolic disturbance which is often unrecognised by patient or practitioner except as some general and obscure trouble of digestion. In such cases early dietetic treatment is of the first importance, and it is in them more especially that the judicious use of cheese, in regard to both quantity and quality, offers resources which no other foodstuff possesses.

I am, Sir, yours faithfully,

Gloucester, July 20th, 1908. Francis T. Bond, M.D. Lond.

\section{REMOVAL OF THE APPENDIX AFTER PERITYPHLITIC ABSCESS.}

To the Editor of ThE LANCET.

SIR, - I have read with interest Mr. W. H. Battle's paper in THE LANCET of July 11th. I entirely agree with him as to the importance of removing the appendix in all cases of appendicital abscess, the abscess being opened first and in a week or ten days afterwards the appendix is removed. This method I have adopted for the last 18 months, and I was led to do so owing to three cases where I had previously opened an abscess having had a recurrent attack from six to nine months after the first operation. The smaller the abscess the greater the importance of removing the appendix. In large abscesses the appendix seems more likely to completely shrivel than in the small ones. It is seldom, however, that we get large abscesses nowadays as they are more promptly operated on, and therefore we may take it as the rule that the appendix is best removed.

I am, Sir, yours faithfully,

J. Crawford Renton, M.D. Edin.

Glasgow, July 13th, 1908.

\section{THE CHURCH OF ENGLAND MISSION TO HOP-PICKERS.}

\section{To the Editor of THE LANCET.}

SIR,-Again I trust you will allow me to appeal through your columns to your many readers, whom otherwise I should not be able to reach, for their practical sympathy with the work we have been doing for the past 30 years among the immigrant hop-pickers. It is not possible for the parochial clergy to minister to the in some cases thousands of immigrants temporarily residing in their parishes and so the mission comes to their aid and sends them trained nurses to minister to the sick, lady workers to help with coffee stalls, club tents, reading rooms, classes, \&c., and evangelists and clergy.

Although there has been a large reduction in the acreage under hops in Kent I expect that our 120 workers will be in touch this season with some 40,000 pickers, for the most part Londoners.

In asking for donations and subscriptions towards the $\$ 250$ I have to raise I would remind your readers that most of our kind helpers only receive their board and lodging expenses.

Bundles of cast-off linen and parcels of literature, of which the supply is never equal to the demand, should be sent to me addressed to Wateringbury Station.

Assuring you of our appreciation of the kind assistance you give us, I am, Sir, yours faithfully, Francis G. OLIPHANT,

Honorary Secretary of the Church of England Mission to Hop-Pickers and Rector of Teston.

\section{ERYTHEMA IRIS TREATED WITH PICRIC ACID.}

To the Editor of THe LANCET.

SrR, - With the limited opportunities of a general prac* titioner in treating this somewhat uncommon disease $\mathrm{I}$ have found the usual methods unsatisfactory. I make bold, therefore, to send you this note, as I found the treatment adopted relieve the symptoms to a marked degree.

Miss - - aged 31 years, had been treated by xie three years ago for erythema iris. The second attack occurred at 